\title{
Digital karyotyping reveals probable target genes at 7q21.3 locus in hepatocellular carcinoma
}

Hui Dong ${ }^{1 *}$, Hongyi Zhang ${ }^{2}$, Jianping Liang ${ }^{3}$, Huadong Yan ${ }^{4}$, Yangyi Chen ${ }^{5}$, Yan Shen ${ }^{5}$, Yalin Kong ${ }^{2}$, Shengyue Wang ${ }^{1}$, Guoping Zhao ${ }^{1,5}$ and Weirong $\operatorname{Jin}^{1,5}$

\begin{abstract}
Background: Hepatocellular carcinoma (HCC) is a worldwide malignant liver tumor with high incidence in China. Subchromosomal amplifications and deletions accounted for major genomic alterations occurred in HCC. Digital karyotyping was an effective method for analyzing genome-wide chromosomal aberrations at high resolution.

Methods: A digital karyotyping library of HCC was constructed and 454 Genome Sequencer FLX System (Roche) was applied in large scale sequencing of the library. Digital Karyotyping Data Viewer software was used to analyze genomic amplifications and deletions. Genomic amplifications of genes detected by digital karyotyping were examined by real-time quantitative PCR. The mRNA expression level of these genes in tumorous and paired nontumorous tissues was also detected by real-time quantitative RT-PCR.
\end{abstract}

Results: A total of 821,252 genomic tags were obtained from the digital karyotyping library of HCC, with 529,162 tags (64\%) mapped to unique loci of human genome. Multiple subchromosomal amplifications and deletions were detected through analyzing the digital karyotyping data, among which the amplification of $7 q 21.3$ drew our special attention. Validation of genes harbored within amplicons at 7q21.3 locus revealed that genomic amplification of SGCE, PEG10, DYNC111 and SLC25A13 occurred in 11 (21\%), 11 (21\%), 11 (21\%) and 23 (44\%) of the 52 HCC samples respectively. Furthermore, the mRNA expression level of SGCE, PEG10 and DYNC111 were significantly up-regulated in tumorous liver tissues compared with corresponding nontumorous counterparts.

Conclusions: Our results indicated that subchromosomal region of 7q21.3 was amplified in HCC, and SGCE, PEG10 and DYNC111 were probable protooncogenes located within the 7q21.3 locus.

\section{Background}

Hepatocellular carcinoma (HCC) is one of the major human malignant tumors worldwide. Accumulation of genetic and epigenetic changes plays an important role in the process of hepatocarcinogenesis. Chromosomal aberration is among the most prevalent genetic alterations observed in HCC [1]. Recurrent chromosomal gains of $1 \mathrm{q}, 6 \mathrm{p}, 8 \mathrm{q}, 17 \mathrm{q}$, and $20 \mathrm{q}$, and losses of $1 \mathrm{p}, 4 \mathrm{q}$, 5q, 6q, 8p, 9p, 10q, 13q, 16q, 17p, 19p, and 22q in HCC have been documented in previous studies [2-7]. Exploring cancer genome in great details always led to the identification of cancer-associated genes (also referred to as target genes) located within the amplified or deleted chromosomal regions. For example, deletion at

\footnotetext{
* Correspondence: dongh@chgc.sh.cn

'Chinese National Human Genome Center at Shanghai, Shanghai 201203, China

Full list of author information is available at the end of the article
}

1p36 locus in HCC was reported to be one of the common mechanisms for inactivation of RUNX3, a putative tumor suppressor gene located within this region [8]. Elevated expression level of PTK2 and EIF3S3 genes in HCC was demonstrated to be significantly correlated with amplification of 8q23-q24, indicating a potential role for these genes in progression of HCC [9].

Recent innovations on molecular genetic techniques allowed investigators to perform genome-wide analysis of chromosomal aberrations at high resolution. Among these techniques, array-based comparative genomic hybridization (aCGH), high-density single nucleotide polymorphism (SNP) arrays and digital karyotyping have been proved to be the most effective tools in discovering abnormal chromosomal features $[7,10,11]$. Instead of generating analog signal intensity in the array-based methods, digital karyotyping is characterized by providing direct, unbiased, precise and quantitative measurement of chromosomal 
aberrations, with a theoretical resolution as high as 0.004 $\mathrm{Mb}$ [12].

In the current study, digital karyotyping was applied to detect chromosomal aberrations in HCC. We found that the amplification at $7 \mathrm{q} 21.3$ locus may contribute to the development or progression of HCC. Gains of $7 q 21$ have been observed in tumors such as prostate cancer, colorectal cancer and HCC [13-15]. Tsuji et al. has identified PEG10 as a putative oncogene located within the amplified 7q21 locus in HCC [16]. Our study highlighted that more target genes including SGCE, DYNC1I1, SLC25A13, as well as PEG10, were harbored within the amplicons at 7q21.3 in HCC. Furthermore, up-regulation of SGCE, DYNC1I1 and PEG10 genes were also observed in HCC. These results indicated that amplification of 7q21.3 may be involved in carcinogenesis of HCC, and SGCE, DYNC1I1 and PEG10 were candidate oncogenes located within 7q21.3 locus.

\section{Methods}

\section{Tissue samples}

Clinical tumorous and corresponding non-tumorous liver tissues were obtained from HBV-positive primary HCC patients who underwent curative surgery. Specimens were kept frozen in liquid nitrogen immediately to avoid any degradation of RNA and/or DNA. Blood of normal individuals was obtained from healthy people who underwent regular physical examination. All samples were collected with informed consent and the study was approved by the Institutional Human Subjects Protection Review Board.

\section{Digital karyotyping}

Genomic DNA was isolated from one tumorous liver tissue using DNeasy kit (Qiagen) according to the manufacture's instruction. Then, $10 \mu \mathrm{g}$ of genomic DNA was used to generate digital karyotyping library as described by Leary et al [17]. However, the concatemers of ditags were not cloned into pZero because 454 Genome Sequencer FLX System (Roche) was applied in large scale sequencing in this study. Instead, the concatemers with adhesive ends of CATG were ligated to a pair of modified adaptors $\mathrm{A}^{+}$ and $\mathrm{B}^{+}$which provide priming regions for the following emulsion PCR and 454 pyrosequencing. The original Adaptor A and B provided by the GS FLX Standard DNA Library Preparation Kit (Roche) were blunt-ended and could not be ligated to concatemers directly. Thus, we designed a modified Adaptor $\mathrm{A}^{+}$and $\mathrm{B}^{+}$with an extruding end which was complementary to the adhesive end of concatemers. The sequences of Adaptor $\mathrm{A}^{+}$and $\mathrm{B}^{+}$were as followings: Adaptor $\mathrm{A}^{+}$forward strand: 5'-CCA TCT CAT CCC TGC GTG TCC CAT CTG TTC CCT CCC TGT CTC AGA CTG CAT G-3'; Adaptor A ${ }^{+}$reverse strand: 5'CAG TCT GAG ACA GGG AGG GAA CAG ATG GGA
CAC GCA GGG ATG AG-3'; Adaptor B ${ }^{+}$forward strand: 5'-Biotin-CCT ATC CCC TGT GTG CCT TGC CTA TCC CCT GTT GCG TGT CTC AGA CTG CAT G-3'; Adaptor $\mathrm{B}^{+}$reverse strand: 5'-CAG TCT GAG ACA CGC AAC AGG GGA TAG GCA AGG CAC ACA GGG GA3'. The underlined basepairs were optional barcode sequences. The following procedures were carried out according to the original protocol [18], and sequencing run was performed on 454 GS FLX instrument. The $21 \mathrm{bp}$ genomic tags were extracted using SAGE2000 software (Invitrogen). The experimentally observed tags were mapped to virtual tags on the genome and their relative frequency was counted to detect genomic amplifications and deletions using Digital Karyotyping Data Viewer software http://cgap.nci.nih.gov/SAGE/DKViewHome. The database of virtual genomic tags was established according to sequences of NCBI Human Genome Assembly Build 37 (released on Aug 2009).

\section{Quantitative PCR}

Genomic DNAs were extracted from tumorous liver tissues of $52 \mathrm{HCC}$ patients and peripheral blood lymphocytes of 52 normal individuals using DNeasy kit (Qiagen). PCR reaction mixture of $25 \mu \mathrm{l}$ was composed of $50 \mathrm{ng}$ genomic DNA, $12.5 \mu \mathrm{l}$ SYBR Premix Ex Taq (TaKaRa), $250 \mathrm{nM}$ of each primer and appropriate volume of $\mathrm{dd}_{2} \mathrm{O}$. The thermal cycles were performed on ABI Prism 7300 apparatus (Applied Biosystems) with conditions of $95^{\circ} \mathrm{C}$ for $10 \mathrm{~s}$, followed by 40 cycles of $95^{\circ} \mathrm{C}$ for $5 \mathrm{~s}$ and $60^{\circ} \mathrm{C}$ for $30 \mathrm{~s}$. Each PCR reaction was performed in triplicate and threshold cycle numbers were averaged. The primers (Table 1 ) were designed using Primer 3 software http://frodo.wi.mit.edu/ primer3/. The repetitive element LINE-1, which is likely to has an equivalent copy number in cancer and normal genomes, was used as an endogenous control for normalization of DNA content.

\section{Quantitative reverse transcription-PCR (RT-PCR)}

Total RNAs were extracted from 32 pairs of tumorous and corresponding non-tumorous liver tissues using TRIzol reagent (Invitrogen), and then treated with

Table 1 Primers used for real-time quantitative PCR

\begin{tabular}{lll}
\hline Genes & Primers & Product Size \\
\hline LINE-1 & F: AAAGCCGCTCAACTACATGG & $149 \mathrm{bp}$ \\
& R: TGCTTTGAATGCGCCCAGAG & \\
SGCE & F: CAGAGACCTTGCTCCCTTG & $193 \mathrm{bp}$ \\
& R: CGTCTIATCAGCCACTGCAA & \\
DYNC1IC & F: ATACAGGACACCCAGGCAAG & $138 \mathrm{bp}$ \\
& R: ACTTCTCGGACCATGTCAGG & \\
SLC25A13 & F: AGGCAGAGCTGGCAAAATAA & $105 \mathrm{bp}$ \\
& R: TCATGCCTTITGATGTGGA & \\
PEG10 & F: CCAGTGTCATCCACCACAG & $219 \mathrm{bp}$ \\
& R: TGCAATTITCCACAGACCAA & \\
\hline
\end{tabular}


RNase-free DNaseI (Promega) prior to reverse transcription. The reverse transcription reactions and following quantitative PCR reactions, as well as statistical analysis were done as previously described [19]. GAPDH was used as internal control for normalizing mRNA level. The sequences of primers used for quantitative RT-PCR were listed in Table 2 .

\section{Statistical analysis}

Student's $t$ test and Bonferroni correction were applied in the statistical analysis of quantitative PCR and RT-PCR data.

\section{Results}

\section{Digital karyotyping of HCC}

We applied 454 pyrosequencing in the current study, and obtained a total of 821,252 genomic tags from the digital karyotyping library of HCC, among which 529,162 tags could be mapped to unique loci of human genome (i.e. filtered tags). By aligning these filtered tags across each chromosome using Digital Karyotyping Data Viewer software with a window size of 20, we identified multiple subchromosomal regions of amplification (fold change $\geq 3$ ) and deletion (fold change $\leq 0.1$ ) (Additional file 1). Among all these chromosomal aberrations, gains of chromosome 7 were of most interest. As many as fifty amplicons with sizes ranging from $287 \mathrm{bp}$ to $212,814 \mathrm{bp}$ were detected on the $q$ arm of chromosome 7 , some of which harbored known genes while some did not (Table 3). The amplified subchromosomal region between 116,320,004 bp and $116,359,984$ bp of $7 \mathrm{q} 31$ harbored MET gene, a wellknown oncogene involved in hepatocarcinogenesis $[20,21]$. The SGCE gene previously reported to be up-regulated in HCC by our group [19], was identified to reside within an amplicon at 94,187,248 bp-94,227,832 bp of 7q21.3. According to the power calculation method developed by Salani et al, a 3-fold amplification covering $38 \mathrm{~kb}$ could be detected with a positive predictive value (PPV) $\geq 95 \%$ if 890,628 experimental tags were obtained [22]. Thus, with 821,252 tags available in this study, the PPV of detecting a 3-fold amplification of 40,584 bp which spans SGCE gene

Table 2 Primers used for real-time quantitative RT-PCR

\begin{tabular}{lll}
\hline Genes & Primers & Product Size \\
\hline GAPDH & F: ATGGGTGTGAACCATGAGAAG & $106 \mathrm{bp}$ \\
& R: AGTTGTCATGGATGACCTTGG & \\
SGCE & F: ATGCAAACACCAGACATCCA & $220 \mathrm{bp}$ \\
& R: TCTGATGTGGCAAGTTCTGC & \\
DYNC1IC & F: TGTGGTCCCCCGTGCATCCT & $127 \mathrm{bp}$ \\
& R: AGGGCGGATGCCCCCTCAAT & \\
SLC25A13 & F: TGGCTGAGGCCCAGAGGCAG & $106 \mathrm{bp}$ \\
& R: GCTCCAGCAACAGAACCCAGACC & \\
PEG10 & F: TCCTGTCTTCGCAGAGGAGT & $111 \mathrm{bp}$ \\
& R: TTCACTTCTGTGGGATGGA & \\
\hline
\end{tabular}

was supposed to be approximately $95 \%$. We also observed that another two genes, DYNC1I1 and SLC25A13 located closely to SGCE, were contained within the amplicons at 7q21.3. Gene expression profile analysis of HCC has implied that SGCE and PEG10 harbored within 7q21.3 locus were putative tumor-associated genes [19]. Thus, our further investigation was focused on 7q21.3 locus, trying to find out more candidate protooncogenes within this amplified subchromosomal region.

\section{Genomic amplification of SGCE, PEG10, DYNC1I1 and SLC25A13 in HCC}

To validate genomic amplifications of SGCE, DYNC1I1 and SLC25A13 detected by digital karyotyping analysis, real-time quantitative PCR was performed in $52 \mathrm{HCC}$ samples and 52 normal individuals. PEG10, a gene located very closely to SGCE in a head-to-head manner, was also selected for examination as a positive control, because both amplification and up-regulation of PEG10 have been observed in HCC $[16,23]$. The schematic illustration of genes located within subchromosomal region of $7 \mathrm{q} 21.3$ (from $94,187,248$ bp to $95,968,724$ bp) was shown in Figure 1. Amplification of genomic DNA was defined as the DNA level of a HCC sample exceeded the mean plus 2 standard deviations of 52 normal individuals [24]. As shown in Figure 2, genomic amplification of SGCE, PEG10, DYNC1I1 and SLC25A13 was observed in 11 (21\%), 11 (21\%), $11(21 \%)$ and $23(44 \%)$ of the 52 HCC samples respectively. In the cases of SGCE, PEG10, and SLC25A13 genes, significant differences were observed between HCC samples and normal individuals, with $p<$ 0.05 after Bonferroni correction. However, the DYNC1I1 gene was likely to be a nominal one, with $p$ value of 0.07 after Bonferroni correction (Additional File 2).

\section{Up-regulated expression of SGCE, PEG10 and DYNC1I1 in} $\mathrm{HCC}$

The transcript expression level of SGCE, PEG10, DYNC111 and SLC25A13 genes in tumorous and paired nontumorous tissues were examined in $32 \mathrm{HCC}$ patients by real-time quantitative RT-PCR. As shown in Figure 3 and Additional File 3, mRNA expression level of SGCE, PEG10 and DYNC1I1 genes were up-regulated in tumorous liver tissues compared with corresponding nontumorous counterparts. However, no significant difference was observed in expression level of SLC25A13 between tumorous and nontumorous liver tissues (data not shown). Taken together, these results suggested that SGCE, PEG10 and DYNC1I1 were putative oncogenes at the amplified 7q21.3 locus in HCC.

\section{Discussion}

In the present study, we applied 454 GS FLX, one of the next-generation sequencing systems, in large-scale 
Table 3 Amplicons on chromosome 7 detected by digital karyotyping

\begin{tabular}{|c|c|c|c|c|}
\hline No. of amplicons & Start Position (bp) & End Position (bp) & Amplification Size (bp) & Known genes contained within amplicons \\
\hline 1 & 85669352 & 85675348 & 5996 & - \\
\hline 2 & 90176250 & 90233199 & 56949 & PFTK1 \\
\hline 3 & 92170683 & 92181579 & 10896 & - \\
\hline 4 & 92402830 & 92489679 & 86849 & CDK6 \\
\hline 5 & 92525776 & 92559603 & 33827 & - \\
\hline 6 & 92621928 & 92628443 & 6515 & - \\
\hline 7 & 94153659 & 94160414 & 6755 & CASD1 \\
\hline 8 & 94187248 & 94227832 & 40584 & SGCE \\
\hline 9 & 95575453 & 95593279 & 17826 & DYNC111 \\
\hline 10 & 95625240 & 95626171 & 931 & DYNC111 \\
\hline 11 & 95626365 & 95634906 & 8541 & DYNC111 \\
\hline 12 & 95857177 & 95888724 & 31547 & SLC25A13 \\
\hline 13 & 95984342 & 95992052 & 7710 & - \\
\hline 14 & 96016428 & 96091391 & 74963 & - \\
\hline 15 & 96091675 & 96098719 & 7044 & - \\
\hline 16 & 96223512 & 96436326 & 212814 & SHFM1 \\
\hline 17 & 96566511 & 96585224 & 18713 & - \\
\hline 18 & 100008093 & 100031196 & 23103 & ZCWPW1, MEPCE \\
\hline 19 & 100188936 & 100202216 & 13280 & FBXO24, PCOLCE \\
\hline 20 & 100212010 & 100322730 & 110720 & MOSPD3, TFR2, ACTL6B, GNB2, GIGYF1, POP7, EPO \\
\hline 21 & 100514082 & 100516140 & 2058 & - \\
\hline 22 & 100594842 & 100615369 & 20527 & MUC12 \\
\hline 23 & 100619990 & 100633128 & 13138 & MUC12 \\
\hline 24 & 100899076 & 100900255 & 1179 & - \\
\hline 25 & 100920401 & 100933959 & 13558 & - \\
\hline 26 & 101043124 & 101046675 & 3551 & EMID2 \\
\hline 27 & 101047291 & 101056595 & 9304 & EMID2 \\
\hline 28 & 101542859 & 101587823 & 44964 & CUX1 \\
\hline 29 & 101708443 & 101725375 & 16932 & CUX1 \\
\hline 30 & 116320004 & 116359562 & 39558 & MET \\
\hline 31 & 116359697 & 116359984 & 287 & MET \\
\hline 32 & 116516633 & 116651559 & 134926 & CAPZA2, ST7, ST7OT1, ST7OT4 \\
\hline 33 & 116832388 & 116859422 & 27034 & ST7, ST7OT3 \\
\hline 34 & 116986284 & 117113342 & 127058 & ASZ1 \\
\hline 35 & 117258567 & 117275904 & 17337 & CFTR \\
\hline 36 & 117301541 & 117312368 & 10827 & CFTR \\
\hline 37 & 117348151 & 117357569 & 9418 & CTTNBP2 \\
\hline 38 & 117371511 & 117376667 & 5156 & CTTNBP2 \\
\hline 39 & 117487299 & 117511084 & 23785 & CTTNBP2 \\
\hline 40 & 117575700 & 117576160 & 460 & - \\
\hline 41 & 117604668 & 117718500 & 113832 & - \\
\hline 42 & 117727390 & 117773948 & 46558 & - \\
\hline 43 & 117862904 & 117882935 & 20031 & ANKRD7 \\
\hline 44 & 117888893 & 117908976 & 20083 & - \\
\hline 45 & 118228295 & 118274830 & 46535 & - \\
\hline 46 & 118275399 & 118309895 & 34496 & - \\
\hline 47 & 118442613 & 118473838 & 31225 & - \\
\hline 48 & 118574464 & 118640670 & 66206 & - \\
\hline 49 & 149702946 & 149746115 & 43169 & - \\
\hline 50 & 153635222 & 153636533 & 1311 & DPP6 \\
\hline
\end{tabular}




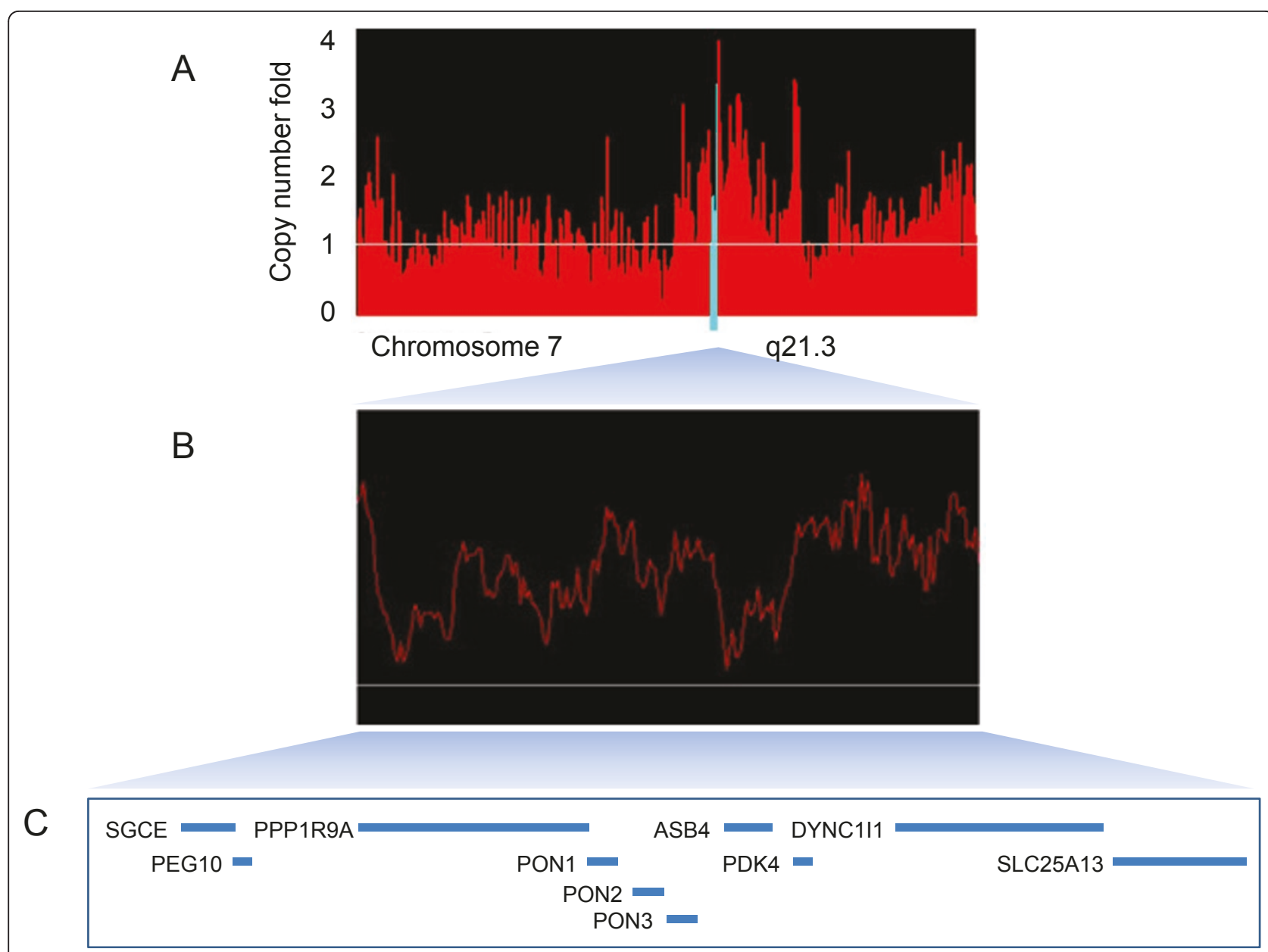

Figure 1 Schematic map of amplicons at 7q21.3 in HCC. (A) Digital karyotyping analysis of chromosome 7 in HCC revealed amplicons at $7 q 21.3$ (indicated by blue bars). (B) Zoom in of the 7q21.3 amplicons. (C) RefSeq genes located within the 7q21.3 amplicons.

sequencing of digital karyotyping library of HCC. To the best of our knowledge, no digital karyotyping data of $\mathrm{HCC}$ has been published in public. In most of the digital karyotyping libraries of human brain and colon available from public database http://cgap.nci.nih.gov/SAGE/ DKViewHome, tags matched to human genome sequences accounted for $62 \sim 69 \%$ of total genomic tags (Additional File 4). In our sequencing results, 64\% $(529,162)$ of the total 821,252 genomic tags were mapped tags, which was quite consistent with published data. Sequentially aligning these tags along each chromosome led to detection of subtle subchromosomal alterations occurred in HCC, among which the amplification of $7 \mathrm{q} 21.3$ drew our special attention.

The role of 7q21 amplification either in HCC cell lines or in primary HCC tumors have been implicated in previous studies $[16,23,25]$. However, within the subchromosome region7q21.3, only PEG10 has been identified as a potential target gene related to progressive development of HCC $[16,23]$. Our study suggested that another two genes,
SGCE and DYNC1I1, may also be HCC-related protooncogenes within the 7q21.3 locus. Genomic amplification of PEG10, SGCE, DYNC1I1 and SLC25A13 were detected by digital karyotyping analysis of $\mathrm{HCC}$, and validated through real-time quantitative PCR. Among $52 \mathrm{HCC}$ samples we examined, eleven $(21 \%)$ of them showed genomic amplification of SGCE, PEG10 and DYNC1I1 respectively, and $23(44 \%)$ of them exhibited genomic amplification of SLC25A13. Further examinations on mRNA expression level of these genes found that SGCE, PEG10 and DYNC1I1 were significantly up-regulated in HCC tumorous tissues compared with the paired nontumorous counterparts. Taken together, these findings indicated that in addition to PEG10, SGCE and DYNC1I1 were likely to be candidate targets for the 7q21.3 locus in HCC.

PEG10 has been identified as a putative target gene for the amplification at $7 \mathrm{q} 21$, as well as a progression related biomarker for HCC [16,23]. SGCE, the epsilon member of sarcoglycan family, was demonstrated to be involved in myoclonus-dystonia syndrome (MDS) which 


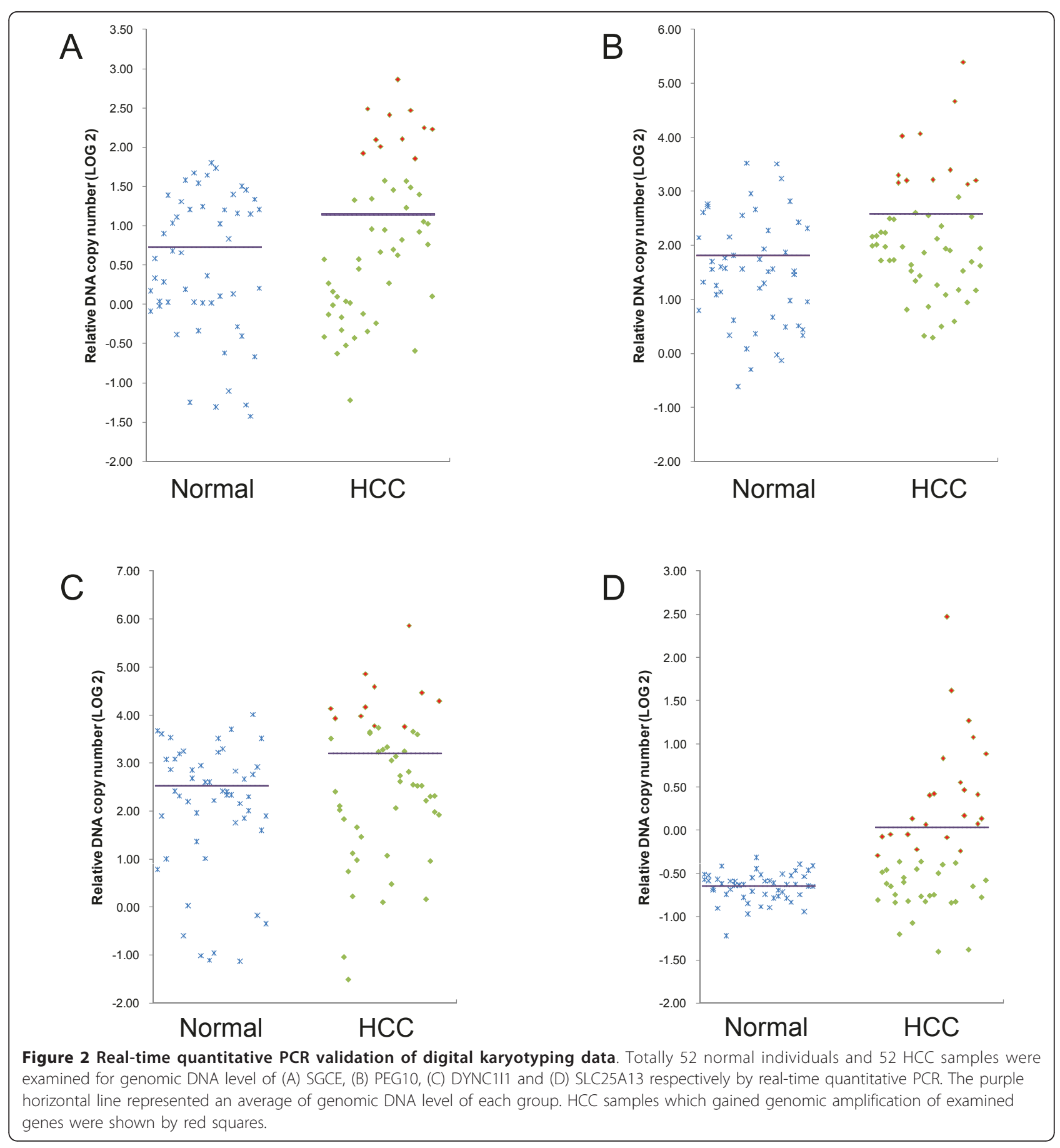

is characterized by rapid myoclonic jerks and dystonia [26]. Recent studies shed light on a role SGCE may play in tumors, as it was up-regulated in a parallel way with PEG10 in both B-cell chronic lymphocytic leukemia and HCC, and showed low or null microsatellite instability in colorectal cancer $[19,27,28]$. However, since the function of SGCE and the mechanism of how it participate in tumor progression remains unknown up to now, its differential expression in HCC could only be regarded as a potential tumor-related marker without any concrete function.

DYNC1I1 gene encoded dynein intermediate chains 1, a component of cytoplasmic dynein complex, and participated in recognizing, binding and transporting vesicles, proteins, and RNAs et al [29,30]. DYNC1I1 was also reported to be a reliable positive marker in testing bone marrow stromal cells prepared for tissue engineering and cell therapy [31]. Our study indicated DYNC1I1 


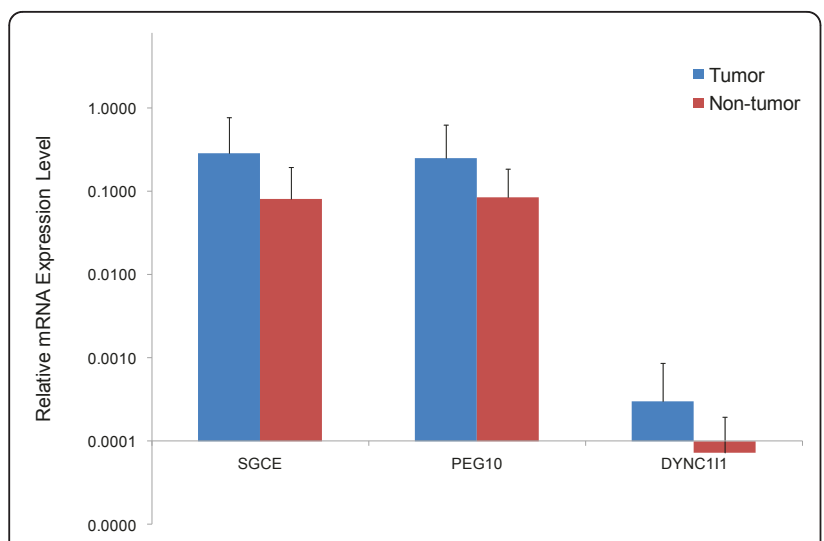

Figure 3 Up-regulated gene expression of SGCE, PEG10 and DYNC111 in HCC. Real-time quantitative RT-PCR was performed in 32 pairs of HCC and corresponding nontumorous liver tissues. Significant up-regulation of mRNA expression level in HCC was observed in SGCE and PEG10 genes ( $p<0.05$ after Bonferroni correction), and DYNC111 was considered as a nominal gene differently expressed in HCC with $p$ value of 0.09 after Bonferroni correction. Blue bars represented expression level of HCC tumorous tissues, red bars represented nontumorous liver tissues, and horizontal bars represented SD values.

was amplified and up-regulated in HCC, pointing to a possible association between this gene and hepatocarcinogenesis. Further studies on DYNC1I1 as well as SGCE are needed to explain the exact roles they may play in HCC and/or other tumors.

\section{Conclusions}

In this study, we examined chromosomal aberrations of HCC on a genome-wide scale and found that subchromosomal region of 7q21.3 was amplified in HCC. Genomic amplification of PEG10, SGCE, DYNC1I1 and SLC25A13 genes which located within the 7q21.3 locus were detected in HCC, and up-regulated expression of genes was also found in cases of PEG10, SGCE and DYNC1I1. These results suggested that besides PEG10, SGCE and DYNC1I1 may also be probable target genes in the subchromosomal region of 7q21.3. Further studies are needed to explore functional roles of PEG10, SGCE and DYNC1I1 genes might play in the initiation and/or progression of HCC.

\section{Additional material}

Additional file 1: Subchromosomal regions of amplification and deletion in HCC detected by digital karyotyping. Digital karyotyping revealed that subchromosomal amplification (fold change $\geq 3$ ) and deletion (fold change $\leq 0.1$ ) occurred in multiple chromosomes in HCC.

Additional file 2: Raw data of real-time quantitative PCR validation for genomic DNA level of SGCE, PEG10, DYNC111 and SLC25A13 genes. Raw data of genomic DNA level of SGCE, PEG10, DYNC111 and SLC25A13 genes in 52 normal individuals and 52 HCC samples were presented in this file. Relative genomic DNA level of SGCE, PEG10,
DYNC111 and SLC25A13 genes were calculated according to the formula

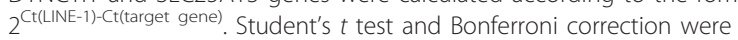
applied in the statistical analysis of raw data.

Additional file 3: Raw data of real-time quantitative RT-PCR detection for SGCE, PEG10 and DYNC111 genes. Raw data of SGCE, PEG10 and DYNC111 gene expression level in 32 pairs of HCC and corresponding nontumorous liver tissues determined by real-time quantitative RT-PCR were presented in this file. Relative expression level of DYNC111, SGCE and PEG10 genes were calculated according to the formula $2^{\mathrm{Ct}(G A P D H)-C t(t a r g e t}$ gene). Student's $t$ test and Bonferroni correction were applied in the statistical analysis of raw data.

Additional file 4: Data summary of 23 digital karyotyping libraries in public database. In the 23 digital karyotyping libraries available at http://cgap.nci.nih.gov/SAGE/DKViewHome, percentage of tags matched to human genome varied from $48 \%$ to $69 \%$, while most of them were between $62 \%$ and $69 \%$.

\section{Abbreviations}

HCC: hepatocellular carcinoma; PEG10: paternally expressed 10; SGCE: sarcoglycan, epsilon; DYNC111: dynein, cytoplasmic 1, intermediate chain 1; SLC25A13: solute carrier family 25, member 13.

\section{Acknowledgements}

This study was supported by Shanghai Commission for Science and Technology (07ZR14083).

\section{Author details}

${ }^{1}$ Chinese National Human Genome Center at Shanghai, Shanghai 201203, China. ${ }^{2}$ Department of Hepatobiliary Surgery, General Hospital of Air Force PLA, Beijing 100036, China. ${ }^{3}$ Hunan Province Tumor Hospital, Changsha 410013, China. ${ }^{4}$ Ningbo No.2 Hospital, Ningbo 315010, China. ${ }^{5}$ National Engineering Center for Biochip at Shanghai, Shanghai 201203, China.

\section{Authors' contributions}

HD designed the experiments, participated in most experiments and drafted the manuscript. HYZ, JPL, HDY and YLK collected the clinical samples. YYC performed the bioinformatics analyses. YS and WRJ constructed the digital karyotyping library and performed QPCR experiments. GPZ and SYW participated in manuscript drafting and revision. All authors read and approved the final manuscript.

\section{Competing interests}

The authors declare that they have no competing interests.

Received: 22 June 2011 Accepted: 19 July 2011 Published: 19 July 2011

\section{References}

1. Villanueva A, Newell P, Chiang DY, Friedman SL, Llovet JM: Genomics and signaling pathways in hepatocellular carcinoma. Semin Liver Dis 2007, 27:55-76.

2. Marchio A, Meddeb M, Pineau P, Danglot G, Tiollais P, Bernheim A, Dejean A: Recurrent chromosomal abnormalities in hepatocellular carcinoma detected by comparative genomic hybridization. Genes Chromosomes Cancer 1997, 18:59-65.

3. Wong N, Lai P, Lee SW, Fan S, Pang E, Liew CT, Sheng Z, Lau JW, Johnson PJ: Assessment of genetic changes in hepatocellular carcinoma by comparative genomic hybridization analysis: relationship to disease stage, tumor size, and cirrhosis. Am J Pathol 1999, 154:37-43.

4. Kusano N, Shiraishi K, Kubo K, Oga A, Okita K, Sasaki K: Genetic aberrations detected by comparative genomic hybridization in hepatocellular carcinomas: their relationship to clinicopathological features. Hepatology 1999, 29:1858-1862.

5. Guan XY, Fang Y, Sham JS, Kwong DL, Zhang Y, Liang Q, Li H, Zhou H, Trent JM: Recurrent chromosome alterations in hepatocellular carcinoma detected by comparative genomic hybridization. Genes Chromosomes Cancer 2000, 29:110-116. 
6. Chang J, Kim NG, Piao Z, Park C, Park KS, Paik YK, Lee WJ, Kim BR, Kim H: Assessment of chromosomal losses and gains in hepatocellular carcinoma. Cancer Lett 2002, 182:193-202.

7. Patil MA, Gütgemann I, Zhang J, Ho C, Cheung ST, Ginzinger D, Li R, Dykema KJ, So S, Fan ST, Kakar S, Furge KA, Büttner R, Chen X: Array-based comparative genomic hybridization reveals recurrent chromosomal aberrations and Jab1 as a potential target for $8 \mathrm{q}$ gain in hepatocellular carcinoma. Carcinogenesis 2005, 26:2050-2057.

8. Mori T, Nomoto S, Koshikawa K, Fujii T, Sakai M, Nishikawa Y, Inoue S, Takeda S, Kaneko T, Nakao A: Decreased expression and frequent allelic inactivation of the RUNX3 gene at 1p36 in human hepatocellular carcinoma. Liver Int 2005, 25:380-388.

9. Okamoto $H$, Yasui $K$, Zhao C, Arii S, Inazawa J: PTK2 and EIF3S3 genes may be amplification targets at $8 \mathrm{q} 23-\mathrm{q} 24$ and are associated with large hepatocellular carcinomas. Hepatology 2003, 38:1242-1249.

10. Midorikawa $Y$, Yamamoto S, Ishikawa S, Kamimura N, Igarashi $\mathrm{H}_{\text {, }}$ Sugimura H, Makuuchi M, Aburatani $\mathrm{H}$ : Molecular karyotyping of human hepatocellular carcinoma using single-nucleotide polymorphism arrays. Oncogene 2006, 25:5581-5590.

11. Wang TL, Maierhofer C, Speicher MR, Lengauer C, Vogelstein B, Kinzler KW Velculescu VE: Digital karyotyping. Proc Natl Acad Sci USA 2002, 99:16156-16161

12. Salani $R$, Chang $C L$, Cope $L$, Wang TL: Digital karyotyping: an update of its applications in cancer. Mol Diagn Ther 2006, 10:231-237.

13. Strohmeyer DM, Berger AP, Moore DH, Bartsch G, Klocker H, Carroll PR, Loening SA, Jensen RH: Genetic aberrations in prostate carcinoma detected by comparative genomic hybridization and microsatellite analysis: association with progression and angiogenesis. Prostate 2004, 59:43-58.

14. Nakao K, Shibusawa M, Ishihara A, Yoshizawa H, Tsunoda A, Kusano M, Kurose A, Makita T, Sasaki K: Genetic changes in colorectal carcinoma tumors with liver metastases analyzed by comparative genomic hybridization and DNA ploidy. Cancer 2001, 91:721-726.

15. Sy SM, Wong N, Lai PB, To KF, Johnson PJ: Regional over-representations on chromosomes $1 \mathrm{q}, 3 \mathrm{q}$ and $7 \mathrm{q}$ in the progression of hepatitis $\mathrm{B}$ virusrelated hepatocellular carcinoma. Mod Pathol 2005, 18:686-692.

16. Tsuji K, Yasui K, Gen Y, Endo M, Dohi O, Zen K, Mitsuyoshi H, Minami M, Itoh Y, Taniwaki M, Tanaka S, Arii S, Okanoue T, Yoshikawa T: PEG10 is a probable target for the amplification at 7q21 detected in hepatocellular carcinoma. Cancer Genet Cytogenet 2010, 198:118-125.

17. Leary RJ, Cummins J, Wang TL, Velculescu VE: Digital karyotyping. Nat Protoc 2007, 2:1973-1986

18. Margulies M, Egholm M, Altman WE, Attiya S, Bader JS, Bemben LA, Berka J, Braverman MS, Chen YJ, Chen Z, Dewell SB, Du L, Fierro JM, Gomes XV, Godwin BC, He W, Helgesen S, Ho CH, Irzyk GP, Jando SC, Alenquer ML, Jarvie TP, Jirage KB, Kim JB, Knight JR, Lanza JR, Leamon JH, Lefkowitz SM, Lei M, Li J, et al: Genome sequencing in microfabricated high-density picolitre reactors. Nature 2005, 437:376-380.

19. Dong $H$, Ge $X$, Shen $Y$, Chen $L$, Kong $Y$, Zhang $H$, Man $X$, Tang $L$, Yuan $H$, Wang $H$, Zhao $G$, Jin W: Gene expression profile analysis of human hepatocellular carcinoma using SAGE and LongSAGE. BMC Med Genomics 2009, 2:5.

20. Boix L, Rosa JL, Ventura F, Castells A, Bruix J, Rodés J, Bartrons R: c-met mRNA overexpression in human hepatocellular carcinoma. Hepatology 1994, 19:88-91.

21. Ueki T, Fujimoto J, Suzuki T, Yamamoto H, Okamoto E: Expression of hepatocyte growth factor and its receptor c-met proto-oncogene in hepatocellular carcinoma. Hepatology 1997, 25:862-866.

22. Salani R, Chang CL, Cope L, Wang TL: Digital karyotyping: an update of its applications in cancer. Mol Diagn Ther 2006, 10:231-237.

23. Ip WK, Lai PB, Wong NL, Sy SM, Beheshti B, Squire JA, Wong N: Identification of PEG10 as a progression related biomarker for hepatocellular carcinoma. Cancer Lett 2007, 250:284-291.

24. Shih leM, Sheu JJ, Santillan A, Nakayama K, Yen MJ, Bristow RE, Vang R, Parmigiani G, Kurman RJ, Trope CG, Davidson B, Wang TL: Amplification of a chromatin remodeling gene, Rsf-1/HBXAP, in ovarian carcinoma. Proc Natl Acad Sci USA 2005, 102:14004-14009.

25. Sy SM, Wong N, Lai PB, To KF, Johnson PJ: Regional over-representations on chromosomes $1 q, 3 q$ and $7 q$ in the progression of hepatitis $B$ virusrelated hepatocellular carcinoma. Mod Pathol 2005, 18:686-692.
26. Zimprich A, Grabowski M, Asmus F, Naumann M, Berg D, Bertram M, Scheidtmann K, Kern P, Winkelmann J, Müller-Myhsok B, Riedel L, Bauer M, Müller T, Castro M, Meitinger T, Strom TM, Gasser T: Mutations in the gene encoding epsilon-sarcoglycan cause myoclonus-dystonia syndrome. Nat Genet 2001, 29:66-69.

27. Kainz B, Shehata M, Bilban M, Kienle D, Heintel D, Krömer-Holzinger E, Le T, Kröber A, Heller G, Schwarzinger I, Demirtas D, Chott A, Döhner H, Zöchbauer-Müller S, Fonatsch C, Zielinski C, Stilgenbauer S, Gaiger A, Wagner $\mathrm{O}$, Jäger $\mathrm{U}$ : Overexpression of the paternally expressed gene 10 (PEG10) from the imprinted locus on chromosome 7q21 in high-risk Bcell chronic lymphocytic leukemia. Int J Cancer 2007, 121:1984-1993.

28. Ortega P, Moran A, Fernandez-Marcelo T, De Juan C, Frias C, LopezAsenjo JA, Sanchez-Pernaute A, Torres A, Diaz-Rubio E, Iniesta P, Benito M: MMP-7 and SGCE as distinctive molecular factors in sporadic colorectal cancers from the mutator phenotype pathway. Int J Oncol 2010, 36:1209-1215.

29. Pfister KK, Shah PR, Hummerich H, Russ A, Cotton J, Annuar AA, King SM, Fisher EM: Genetic analysis of the cytoplasmic dynein subunit families. PLoS Gene 2006, 2:e1

30. Kardon JR, Vale RD: Regulators of the cytoplasmic dynein motor. Nat Rev Mol Cell Biol 2009, 10:854-865.

31. Igarashi A, Segoshi K, Sakai Y, Pan H, Kanawa M, Higashi Y, Sugiyama M, Nakamura K, Kurihara H, Yamaguchi S, Tsuji K, Kawamoto T, Kato Y: Selection of common markers for bone marrow stromal cells from various bones using real-time RT-PCR: effects of passage number and donor age. Tissue Eng 2007, 13:2405-2417.

Pre-publication history

The pre-publication history for this paper can be accessed here: http://www.biomedcentral.com/1755-8794/4/60/prepub

doi:10.1186/1755-8794-4-60

Cite this article as: Dong et al:: Digital karyotyping reveals probable target genes at 7q21.3 locus in hepatocellular carcinoma. BMC Medical Genomics 2011 4:60.

\section{Submit your next manuscript to BioMed Central and take full advantage of:}

- Convenient online submission

- Thorough peer review

- No space constraints or color figure charges

- Immediate publication on acceptance

- Inclusion in PubMed, CAS, Scopus and Google Scholar

- Research which is freely available for redistribution

Submit your manuscript at www.biomedcentral.com/submit
C) Biomed Central 